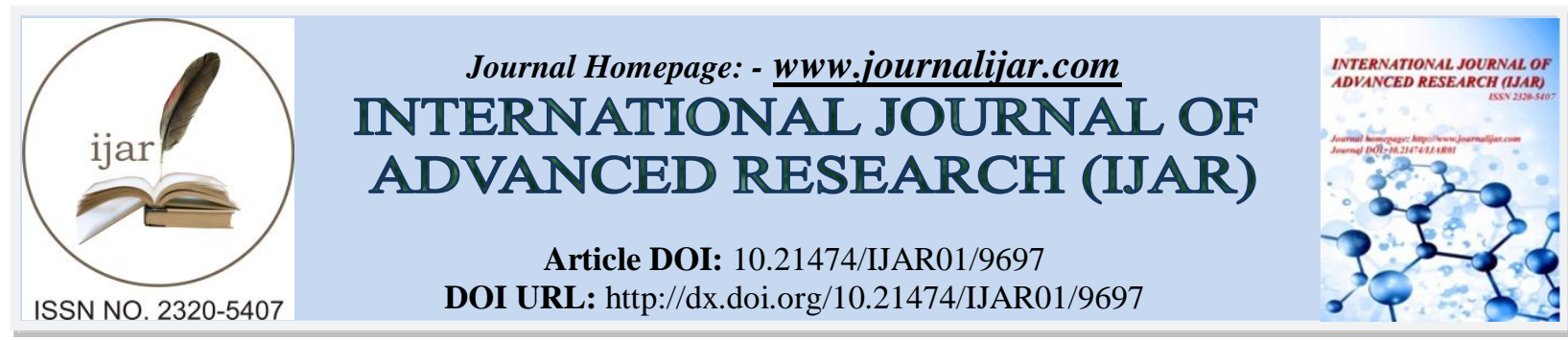

RESEARCH ARTICLE

\title{
UVA/TIO 2 SYSTEM FOR DECONTAMINATION OF POLLUTED WATERS BY CANCER DRUGS: IFOSFAMIDE AND CYCLOPHOSPHAMIDE.
}

\author{
N'guettia Kossonou Roland ${ }^{1}$, Soro Donafologo Baba ${ }^{2}$, Aboua Kouassi Narcisse ${ }^{2}$, Gombert Bertrand ${ }^{3}$, Méité \\ Ladji $^{2}$, Dembélé Ardjouma ${ }^{1}$, Mamadou Koné ${ }^{2}$ and Traoré Karim Sory ${ }^{2}$. \\ 1. Laboratoire National d'Appui au Développement Agricole (LANADA) 04 BP 612 Abidjan 04, Côte d'Ivoire. \\ 2. Laboratoire des Sciences de l'Environnement, Université Nangui Abrogoua, Abidjan, Côte d'Ivoire. \\ 3. Institut de Chimie des Milieux et Matériaux de Poitiers (IC2MP), Université de Poitiers, CNRS, F-86073, \\ France.
}

\section{Manuscript Info}

Manuscript History

Received: 08 July 2019

Final Accepted: 10 August 2019

Published: September 2019

Key words:-

Ifosfamide, Cyclophosphamide, UVA-

$\mathrm{TiO}_{2}$, ultra-pure water, Drinking water.

\section{Abstract}

The aim of this study is to show potential of photocatalysis for degradation of ifosfamide and cyclophosphamide in matrix water. Effect of titanium dioxide $\left(\mathrm{TiO}_{2}\right)$ and the matrices water have been studied. UVA/ $/ \mathrm{TiO}_{2}$ tests has been made in a photoreactor equipped with a UVA lamp. Results showed that more than $80 \%$ abatement is obtained after 8 hours of irradiation in ultra-pure water for 0.1 to $1 \mathrm{~g} / \mathrm{L}$ $\mathrm{TiO}_{2}$ and in tap water respectively for concentrations of $0.5 \mathrm{~g} / \mathrm{L}$ to 1 $\mathrm{g} / \mathrm{L} \mathrm{TiO}_{2}$. Rate of degradation increased for concentrations ranging from 0.1 to $0.5 \mathrm{~g} / \mathrm{L} \mathrm{TiO}_{2}$ in ultrapure water solutions. However, this rate is increased for $1 \mathrm{~g} / \mathrm{L}$ of $\mathrm{TiO}_{2}$ in the tap water. This difference highlights influence of chemical quality of the matrix to be depolluted. total organic carbon is greater than $70 \%$ for $1 \mathrm{~g} / \mathrm{L}$. Results have indicated the photocatalytic process is effective for the degradation of pharmaceutical molecules in water matrix. In future, titanium dioxide would to fix on non-polluting materials will be undertaken order mix in the material. This will permit to avoid suspension and reduce treatment costs and toxicity after photocatalytic treatments of wastewater.

Copy Right, IJAR, 2019,. All rights reserved.

\section{Introduction:-}

Diagnosis of cancerous diseases in children has led to the marketing of new molecules for treatment of these patients in the word. The most commonly used drugs are 5-fluorouracil, cyclophosphamide and ifosfamide [1]. Administration of these drugs has solved a large number of public health problems in pediatric oncology departments [2],[3]. But it should be noted that these patients release these molecules in their bioactive form into wastewater. Excreted portion of anti-cancer drugs is between 20 and $50 \%$ [4]. For example, 5-fluorouracil, cyclophosphamide, ifosfamide, gemcitabine, bleomycin, cytarabine, etoposide, methotrexate, etc. have often been detected in wastewater effluents and surface waters that could be used to supply large cities with drinking water [5], [6]. This contaminated water is used for peri-urban agriculture. This contamination affects health of ecosystems and alters their balance. Primarily, aquatic ecosystems that receive wastewater from health care facilities, creating nonpoint source pollution. pollution of this biotope influences life of aquatic fauna and flora in their reproductive system and at the end of the chain, man who consumes them in various forms [3];[7]; [8]. In a context of climate change and water scarcity in some regions of the world, treatment of contaminated water could generate high

Corresponding Author:-N'guettia Kossonou Roland.

Address:-Laboratoire National d'Appui au Développement Agricole (LANADA) 04 BP 612 Abidjan 04, 
operating costs. For example, conventional water treatment methods such as sedimentation, chemical and membrane filtration technologies involve high operating costs and could generate toxic secondary pollutants in the aquatic ecosystem [9]. These toxic contaminants, which are highly redundant, have raised awareness and led to the introduction of increasingly stringent environmental legislation [10], [11]. Removal of these drug residues from wastewater requires rustic techniques to mineralize them into water and carbon dioxide, this process requires oxidation techniques that respect health of environment, i.e. powerful oxidants such as hydroxyl radicals $\left(\mathrm{OH}^{\circ}\right)$. Implementation of these advanced oxidation processes has made it possible to clean several water matrices contaminated with residues of dyes, pesticides and other organic molecules used in industries. It is clear that it is necessary to use processes that are inexpensive, accessible and practical for all. Titanium dioxide is part of this range of oxidants that break down organic pollutants such as anti-cancer drugs until they are completely mineralized [12].

Among the advanced oxidation processes, heterogeneous photocatalysis using semiconductor catalysts $\left(\mathrm{TiO}_{2}, \mathrm{ZnO}\right.$, $\mathrm{Fe}_{2} \mathrm{O}_{3}, \mathrm{CdS}, \mathrm{GaP}$ ) has demonstrated its effectiveness in degrading a wide range of refractory organic materials into easily biodegradable compounds and eventually into complete mineralization of carbon dioxide $\left(\mathrm{CO}_{2}\right)$ and water $\left(\mathrm{H}_{2} \mathrm{O}\right)$ [13]. Among semiconductor catalysts, titanium dioxide $\left(\mathrm{TiO}_{2}\right)$ has received the most attention in the field of research and development $(\mathrm{R} \& \mathrm{D})$ of photocatalytic technologies [14]. Its main advantage is the use of $\mathrm{TiO}_{2}$, which is chemically and biologically inert, inexpensive, stable and readily available on the market [15]. Hydroxyl radicals $\left(\mathrm{OH}^{\bullet}\right)$ were selected in this study as one of the most potential oxidants that can be applied to water depollution because they meet a set of criteria [16]. This work shows the potential for decontamination of waters containing ifosfamide and cyclophosphamide. The aim is to evaluate effect of the catalyst's titanium dioxide concentration on degradation of these cancer molecules.

\section{Material And Methods:-}

\section{Reagents and solvents}

All chemicals used are of quality and purity above $98 \%$. Ifosfamide (IF) and cyclophosphamide (CP) are provided from Sigma-Aldrich (Steinheim, Germany). These molecules are illustrated on the figure 1. Pharmaceutical molecules were used in this state of purity. Some characteristics of these cancer drugs are illustrated on figure 1. We used acetonitrile (ACN) and formic acid which are HPLC grade which provided by Carlo Erba reagents (France). Titanium dioxide (Degussa P25) was obtained from Degussa AG (Germany). This crystal contains $75 \%$ anatase and $25 \%$ rutile.

(a)
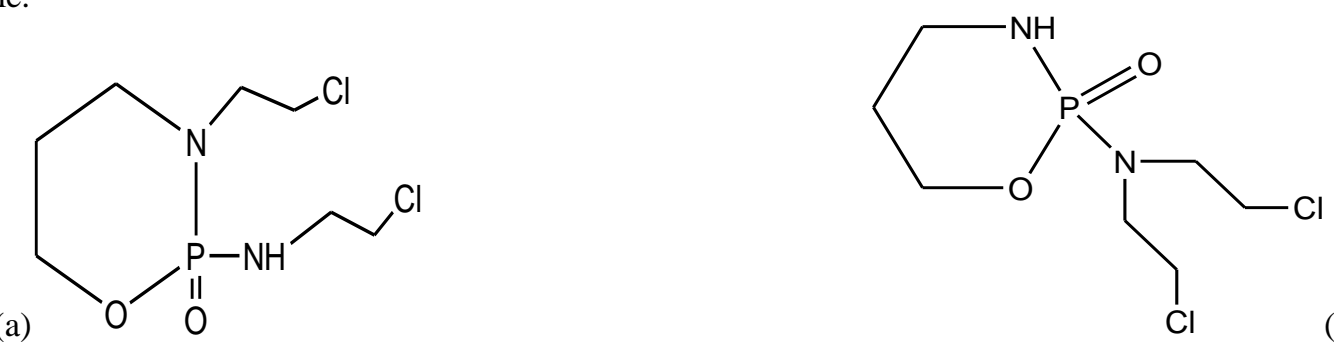

Figure 1:-Structure of anti-cancers molecules: Ifosfamide (a), Cyclophosphamide (b)

\section{Photocatalytic reactor}

Reactor is a discontinuous cylindrical (volume equal 2 liters). The Degussa P25 titanium dioxide has a specific mean surface size (BET) of $50 \pm 15 \mathrm{~m}^{2} / \mathrm{g}$. It was used in suspension. A magnetic agitation bar was placed in the bottom of the reactor to maintain mixture of uniform solution. Temperature was maintained at $25^{\circ} \mathrm{C}$ using a thermostatic bath. A black UVA light lamp (Sylvania, $8 \mathrm{~W}, 365 \mathrm{~nm}$ ) was housed in quartz tube and inserted vertically into the reactor. This lamp emits radiation in the range $350 \mathrm{~nm}-400 \mathrm{~nm}$.

\section{Experimental protocol}

Photocatalysis experiments were performed in the presence of $0.1 \mathrm{~g} / \mathrm{L} ; 0.5 \mathrm{~g} / \mathrm{L}$ and $1 \mathrm{~g} / \mathrm{L} \mathrm{TiO}$. Prior to irradiation (photocatalysis experiments), suspension was agitated in the dark for 30 minutes to achieve the adsorption equilibrium between the surface of the catalyst and the pharmaceutical compounds. Various solutions prepared with ultra-pure water and tap water were spiked at varying concentrations of each drug molecule. Aliquots were filtered through a cellulose syringe filter (PTFE, $0.45 \mu \mathrm{m}$ ) prior to their analysis. Photodegradation tests were performed for 480 minutes. 


\section{Water matrices dilution}

Solutions were prepared in two different matrices which are ultra-pure water and tap water intended for human consumption. Ultra-pure water is of the quality Milli Q Milli RX75/Synergy 185 (Millipore) of resistivity 18 $\mathrm{M} \Omega / \mathrm{cm}$ and a dissolved organic carbon (DOC) content less than $0,1 \mathrm{mg} \mathrm{C} / \mathrm{L}$. Characteristics of drinking water of the distribution network of city Poitiers (France) were determined by ionic chromatography of pump Dionex 3000 ICS. These values are shown in table 1.

Table 1:-Drinking Water parameters values

\begin{tabular}{|l|l|}
\hline Parameters & Values \\
\hline $\mathrm{pH}$ & 7.5 \\
\hline Conductivity & $560 \mu \mathrm{S} / \mathrm{cm}$ \\
\hline Title Alkalimetry (TAC) & $29^{\circ} \mathrm{F}$ \\
\hline Calcium ions $\left(\mathrm{Ca}^{2+}\right)$ & $120 \mathrm{mg} / \mathrm{L}$ \\
\hline Chlorides ions $\left(\mathrm{Cl}^{-}\right)$ & $7 \mathrm{mg} / \mathrm{L}$ \\
\hline
\end{tabular}

\section{Visible UV Spectroscopy analysis}

Absorption spectra of molecules were obtained with solutions of $20 \mathrm{mg} / \mathrm{L}$ prepared with purified water at free $\mathrm{pH}$ or by taking into account water solubility. Visible UV spectra were plotted with a double-beam SAFAS 190 (double Energy Transfer) spectrophotometer with quartz vats of $1 \mathrm{~cm}$ optical path.

\section{High Performance liquid chromatography analysis}

A high-performance liquid chromatography (HPLC) system model Alliance 2695 Waters coupled with a diode barrette detector (Waters 2998 PDA) has been used for identification and quantification of pharmaceutical products. Mobile phase consists of ultra-pure water acidified with formic acid $(0.1 \%)$ (A) and acetonitrile (B) acidified with formic acid $(0,1 \%)$. Separation was performed with a Kromasil column of type $(250 \mathrm{~mm}$ x $4.6 \mathrm{~mm}, 5 \mu \mathrm{m})$ in gradient mode for $20 \mathrm{~min}$. Detection was performed at $195 \mathrm{~nm}$. Retention time is 4.30 minutes.

\section{Kinetics of degradation}

Kinetics of degradation of organic compounds by photocatalyst following a kinetic of order 1 and the half-life time of photodegradation of pharmaceutical pollutants were determined (Equations 1,2)

$\ln \frac{\mathrm{C}_{0}}{\mathrm{C}}=\mathrm{kt} \quad$ (1)

$\mathrm{t}_{1 / 2}=\frac{\ln 2}{\mathrm{k}}$

$\ln \left(\mathrm{C}_{0} / \mathrm{C}\right)=\mathrm{kt}, \mathrm{C}(\mathrm{mol} / \mathrm{L})$ solution concentration at instant $\mathrm{t}(\mathrm{mol} / \mathrm{L}), \mathrm{C}_{0}(\mathrm{~mol} / \mathrm{L})$ initial concentration at $\mathrm{t}=0 \mathrm{~min}$, $\mathrm{k}_{\text {app }}\left(\mathrm{min}^{-1}\right)$ rate constant and $\mathrm{t}(\mathrm{min})$ reaction time.

\section{Percentage of removal of anti-cancers drugs}

We calculate percentage of degradation of cyclophosphamide and ifosfamide initially ant finally experiences (Equations 3,4).

$$
\begin{aligned}
& (\mathrm{IF})=\frac{(\mathrm{IF})_{\mathrm{i}}-(\mathrm{IP})_{\mathrm{t}}}{(\mathrm{IP})_{\mathrm{i}}} \times 100(3) \\
& (\mathrm{CP})=\frac{(\mathrm{CP})_{\mathrm{i}}-(\mathrm{CP})_{\mathrm{t}}}{(\mathrm{CP})_{\mathrm{i}}} \times 100(4)
\end{aligned}
$$

(IF)i and (CP)i are initials concentrations of ifosfamide and cyclophosphamide (mol/L)

$(\mathrm{IF})_{\mathrm{t}}$ and $(\mathrm{CP})_{\mathrm{t}}$ are the finals concentrations of ifosfamide concentration at time $(\mathrm{t})(\mathrm{mol} / \mathrm{L})$.

\section{Total Organic Carbon (COT)}

For determination of total organic carbon, TOC-CV (SHIMAZU) model COT was used. Percentage of TOC is determined by equation 5 :

$$
\cot (\%)=\frac{\operatorname{COT}_{\mathrm{i}}-\operatorname{coT}_{\mathrm{t}}}{\operatorname{coT}_{\mathrm{i}}} \times 100(5)
$$

$\mathrm{COT}_{\mathrm{i}}$ is initial quantity of total organic carbon $(\mathrm{mg} / \mathrm{L}), \mathrm{COT}_{\mathrm{t}}$ quantity of total organic carbon at time $\mathrm{t}(\mathrm{mg} / \mathrm{L})$. 


\section{Results and discussion:- \\ Photocatalysis of $\mathrm{TiO}_{2}$}

Visible UV spectra of ifosfamide and cyclophosphamide are shown in figure 2 . These spectra were obtained with a concentration of $\mathrm{C}_{0}=20 \mathrm{mg} / \mathrm{L}$ because these molecules are difficult to detect at low concentrations in the domain of visible UV (200 nm-400 nm). Spectrum of UVA lamp and those of pharmaceutical molecules were superimposed to see overlapping areas. Appearance of the UV-visible spectrum of ifosfamide and cyclophosphamide showed that these molecules absorbs very weakly in the UV-visible domain especially since their absorption peaks are equal to $192 \mathrm{~nm}$. Indeed, chromophores that absorb at this length are amide functions that are found in the chemical structure of ifosfamide and cyclophosphamide. This is why these pharmaceutical molecules are classified among most resistant pharmaceutical substances to photodegradation in the UV-visible field among a group of 30 pharmaceuticals and personal care products [17]. Ifosfamide and cyclophosphamide cannot be degraded by direct photolysis under irradiation of the UVA lamp. This information indicated that ifosfamide and cyclophosphamide could to remove by photocatalyst process.

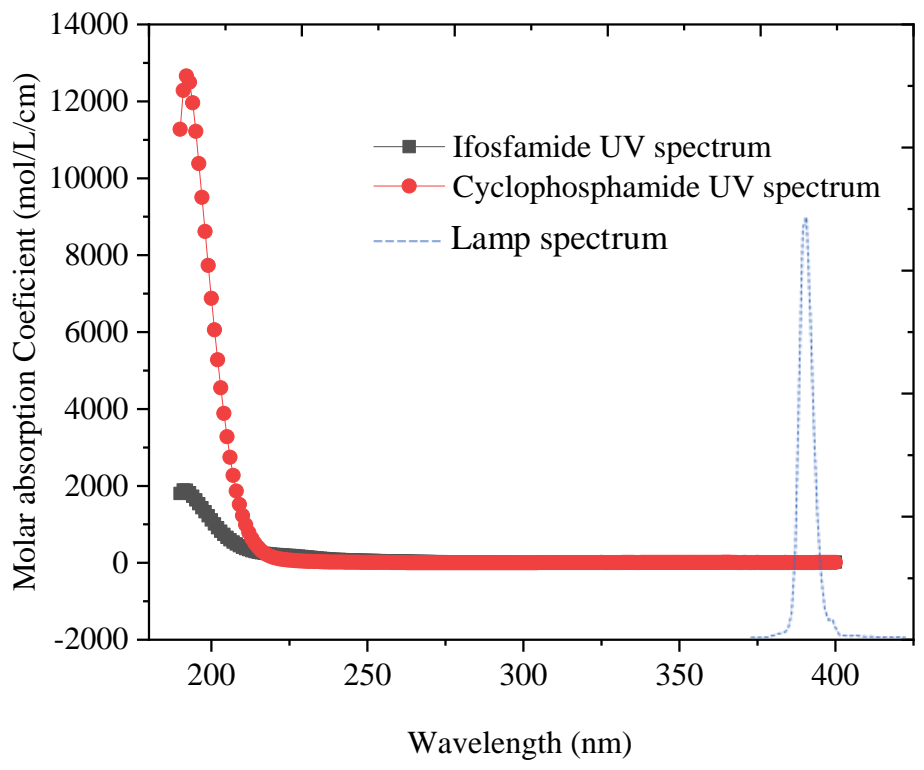

Figure 2:-Superposition of visible UV spectra ifosfamide and cyclophosphamide, $\mathrm{C}_{0}=20 \mathrm{mg} / \mathrm{L}, \mathrm{pH}=6$

\section{Effect of catalyst concentration}

Efficacy of photocatalytic process was tested to remove ifosfamide and cyclophosphamide in ultra-pure water. This test has permit to see effect of titanium dioxide on degradation of these molecules. Kinetics are shown in figures 3 and 4. Firstly, we carried out experiments of adsorption and photolysis. Results showed that these molecules are not eliminated by these processes. These results confirm our hypothesis in the absorption spectroscopic UV paragraph. Again, similar studies have been found by Kim and Tanaka, [17], Lutterbeck et al. [18] and Fabiańska et al, [19]. Secondary, the photocatalysis experiments of cancer drugs were performed in presence of $\mathrm{TiO}_{2}$. At beginning of each experiment, after addition of the suspension catalyst in drug solution, we have left reaction in dark for a period of 30 minutes: This corresponds to the negative times on abscissa axe in this figure 2 . This period shows that there is no significant elimination of drugs by adsorption alone with $\mathrm{TiO}_{2}$ in our operating conditions. The time equal zero minute $(0$ minute) corresponds to the beginning of the exposure of the solution to the light UVA. Then, this is the beginning of the photocatalysis test itself. Results showed a rapid decrease in the initial concentration during the 200 minutes for all $\mathrm{TiO}_{2}$ concentrations. 


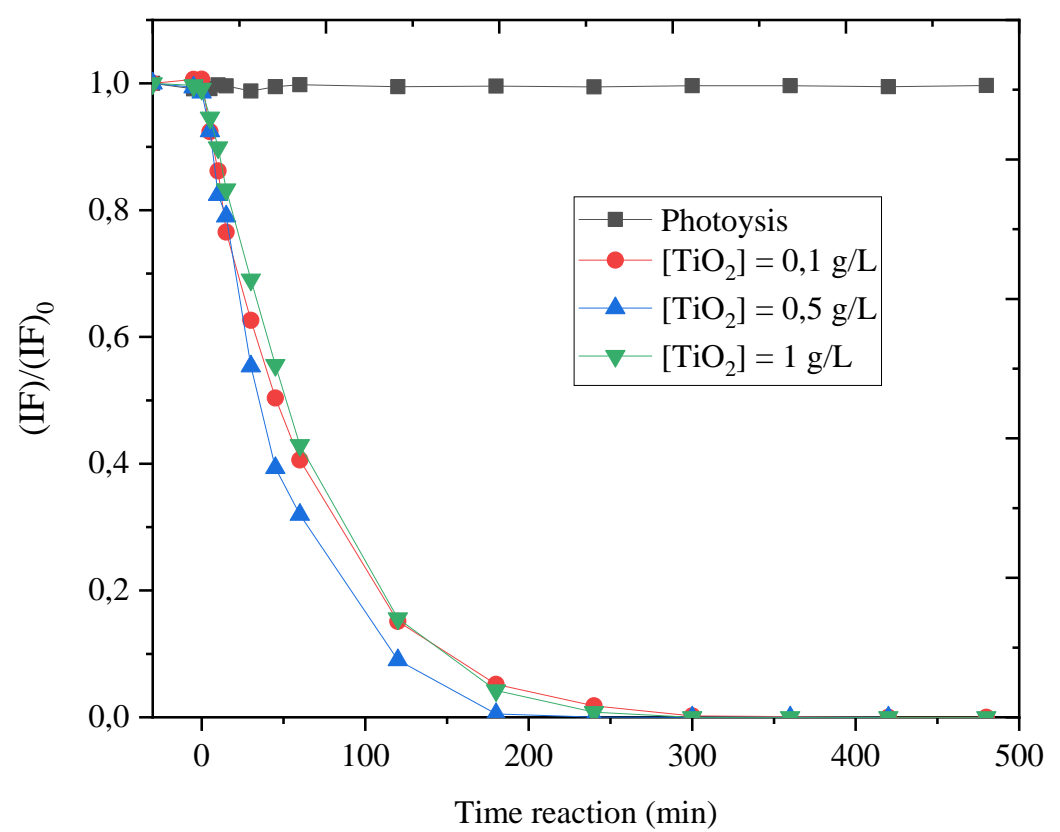

Figure 3:-Effect of $\mathrm{TiO}_{2}$ concentrations on degradation of ifosfamide in ultra-pure water, $\mathrm{C}_{0}=20 \mathrm{mg} / \mathrm{L} \mathrm{pH}=6, \mathrm{~T}=$ $25{ }^{\circ} \mathrm{C}$

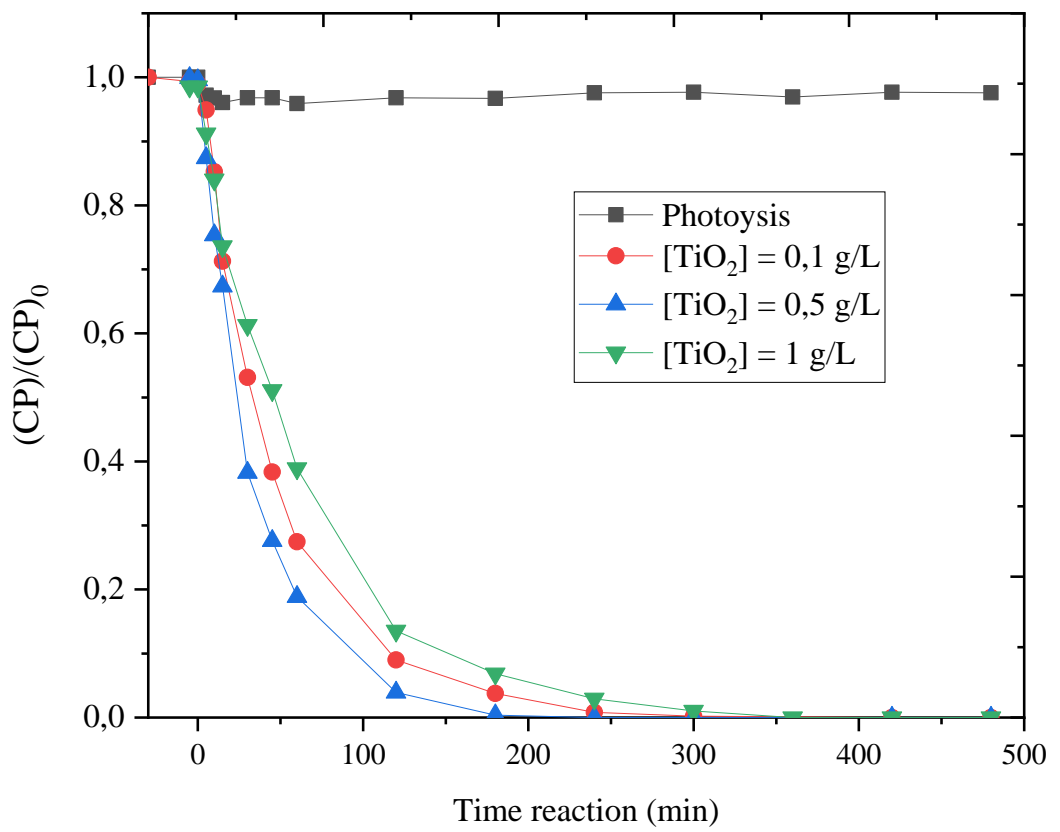

Figure 4:-Effect of $\mathrm{TiO}_{2}$ concentrations on degradation of cyclophosphamide in ultra-pure water, $\mathrm{C}_{0}=20 \mathrm{mg} / \mathrm{L} \mathrm{pH}$ $=6, \mathrm{~T}=25^{\circ} \mathrm{C}$

In table 3, kinetic constants are $2.1 .10^{-1} ; 1.84 .10^{-1} \mathrm{~min}^{-1}$ for 0.1 and $0.5 \mathrm{~g} / \mathrm{L}$ of $\mathrm{TiO}_{2}$ respectively ifosfamide and cyclophosphamide. We have observed an acceleration of degradation of the molecules with the increase in the mass 
of catalyst suspended between 0.1 and $0.5 \mathrm{~g} / \mathrm{L} \mathrm{TiO}_{2}$. These results indicated an important production of $\mathrm{OH}^{\circ}$ radicals. These observations are similar to those of $\mathrm{Lin}$ and $\mathrm{Lin}$, (2014). For these authors, $\mathrm{TiO}_{2}$ concentrations ranging from $0.1 \mathrm{~g} / \mathrm{L}$ to $0.5 \mathrm{~g} / \mathrm{L} \mathrm{TiO}_{2}$ increase the number of active catalytic sites available for photocatalytic reactions. On other hand, for concentration of $1 \mathrm{~g} / \mathrm{L}$ of catalyst, rate of degradation decreases. This decrease is attributed to a screen effect of the excess catalyst that can cover a portion of photosensitive surface of suspended of $\mathrm{TiO}_{2}$. This turbidity reduces the transmission of light within the solution leading to low light intensity reaching surface of catalyst [21],[12]

Table 3:- Kinetic parameters of photocatalytic degradation of ifosfamide and cyclophosphamide in ultra-pure water

\begin{tabular}{|l|l|l|l|}
\hline Cancers drugs & {$\left[\mathrm{TiO}_{2}\right](\mathrm{g} / \mathrm{L})$} & $\mathrm{k}_{\mathrm{app}}\left(\mathrm{min}^{-1}\right)$ & $\mathrm{t}_{1 / 2}(\mathrm{~min})$ \\
\hline \multirow{5}{*}{ Ifosfamide } & 0.1 & $1.6 .10^{-2}$ & 62 \\
\cline { 2 - 4 } & 0.5 & $2.1 .10^{-2}$ & 51 \\
\cline { 2 - 4 } & 1 & $1.8 .10^{-3}$ & 60 \\
\hline \multirow{3}{*}{ Cyclophosphamide } & 0.1 & $1.5 .10^{-2}$ & 67 \\
\cline { 2 - 4 } & 0.5 & $1.84 .10^{-2}$ & 54 \\
\cline { 2 - 4 } & 1 & $1.6 .10^{-3}$ & 62 \\
\hline
\end{tabular}

\section{Water matrix Effect}

In order to study influence of the nature of dilution matrix, we have carried out similar experiments of photocatalysis but this time in solution in tap water. In fact, drinking water supply system of the city of Poitiers (France) is characterized by a high carbonate content $\left(35^{\circ} \mathrm{F}\right)$. Kinetics of degradation are carried over to figures 4 and 5 . Unlike what we have found that in ultra-pure water, rate of degradation increases with higher concentrations of catalyst up to $1 \mathrm{~g} / \mathrm{L}$.

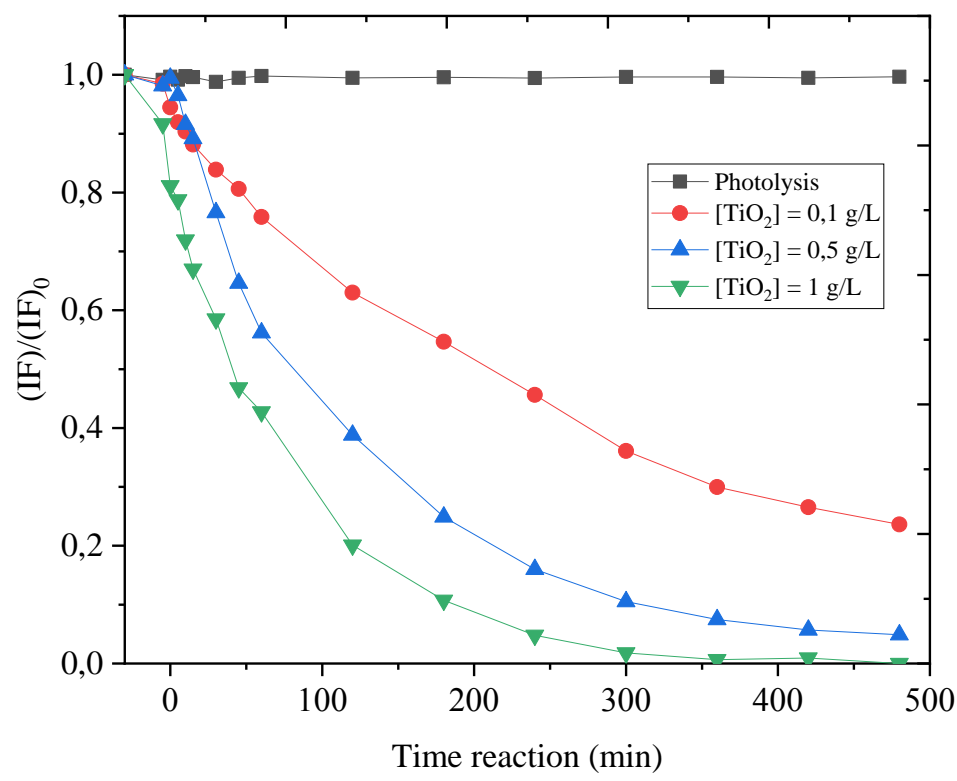

Figure 4:-Kinetics of degradation of ifosfamide by photocatalysis in water tap, $\mathrm{C}_{0}=20 \mathrm{mg} / \mathrm{L} \mathrm{pH}=7.5, \mathrm{~T}=25^{\circ} \mathrm{C}$ 


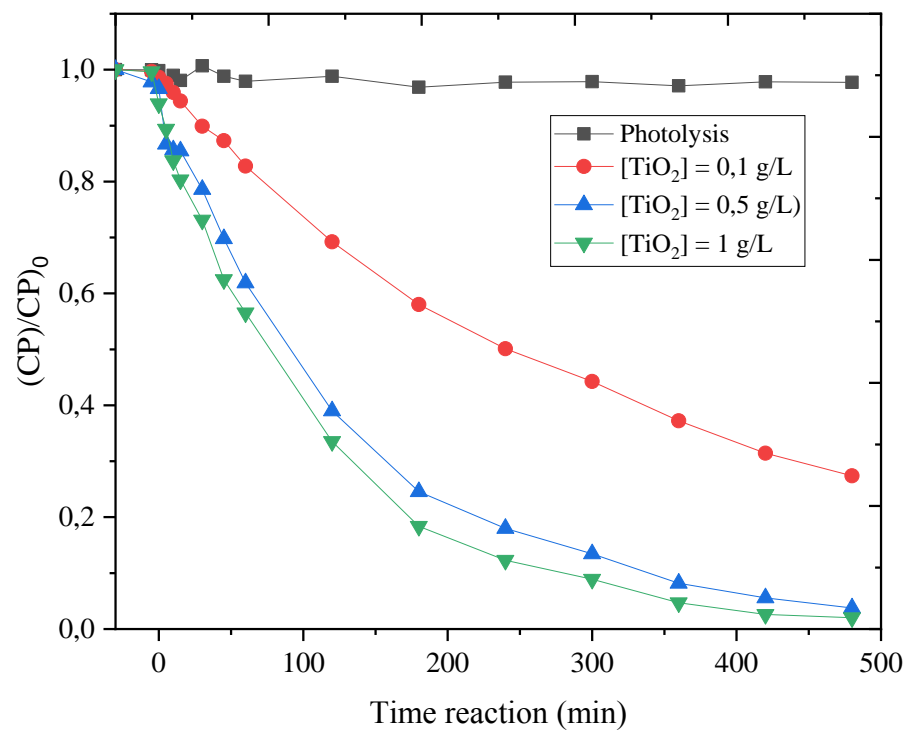

Figure 5:- Kinetics of degradation of cyclophosphamide by photocatalysis in water tap, $\mathrm{C}_{0}=20 \mathrm{mg} / \mathrm{L} \mathrm{pH}=7.5, \mathrm{~T}=$ $25^{\circ} \mathrm{C}$

These results highlight influence of physical and chemical quality on photocatalytic activity. Indeed, carbonates ions $\left(\mathrm{HCO}_{3}{ }^{-}\right)$and chloride ions $\left(\mathrm{Cl}^{-}\right)$ions present in tap water $(\mathrm{pH}=7.5)$ are in competition with organic molecules opposite free radicals. These ions are radical traps. This is why we have observed low rates of degradation in these tap water matrices compared to those obtained in the ultra-pure water matrices [22-24]. The presence of anions may affect photocatalytic activity in water matrices by trapping the $\mathrm{OH}^{*}$ radicals. Chloride $\left(\mathrm{Cl}^{-}\right)$ions present in tap water, which also come from degradation of cyclophosphamide and ifosfamide molecules, can be incorporated into electron-holes [24]. This prevents a recombination of electron-hole pairs [25].

\section{Comparison of degradation kinetics in matrix waters}

We also made a comparison of kinetic constants determined in ultra-pure (EUP) water solutions and in those of tap water (ER) as a function of concentration of catalyst in suspension. These $\mathrm{pH}$ values of solutions aqueous are similar $(\mathrm{pH}=7.5)$. These results are shown on figures 6 and 7. We observed that unlike kinetic constants obtained during experiments in ultra-pure water solutions, those obtained with tap water solutions are very low. These results indicate that rate of reaction depends on the concentration of photocatalyst. This shows that the addition of more $\mathrm{TiO}_{2}$ in reaction medium increases total surface exposed to light so that more free radicals would be generated. Also, this increase in light could be explained by formation of $\mathrm{TiO}_{2}$ aggregates in tap water solutions unlike ultra-pure water solutions [26]. 




Figure 6:-Kinetic constants during photocatalytic degradation of ifosfamide



Figure 7:-Kinetic constants during photocatalytic degradation of cyclophosphamide

\section{Mineralization kinetics}

Figures 8 and 9 shows rates of mineralization and phototransformation of ifosfamide and cyclophosphamide in ultrapure water. The results obtained showed that high mineralization rates were higher than $70 \%$ for $0.5 \mathrm{~g} / \mathrm{L}$ and $1 \mathrm{~g} / \mathrm{L}$ of $\mathrm{TiO}_{2}$ and less than $50 \%$ for $0.1 \mathrm{~g} / \mathrm{L}$ in ultra-pure water after 480 minutes of experience. These mineralization rates increase with catalyst concentrations. Mineralization is slower compared to the kinetics of phototransformation of mother molecules. In fact, parent molecules are transformed into by-products before they are mineralized, and mineralization of the by-products takes place for a relatively long time. This translates a competition between the parent molecule and the by-products and between the by-products themselves opposite radicals $\mathrm{OH}^{*}$. 




Figure 8:-Rate of mineralization and degradation of ifosfamide

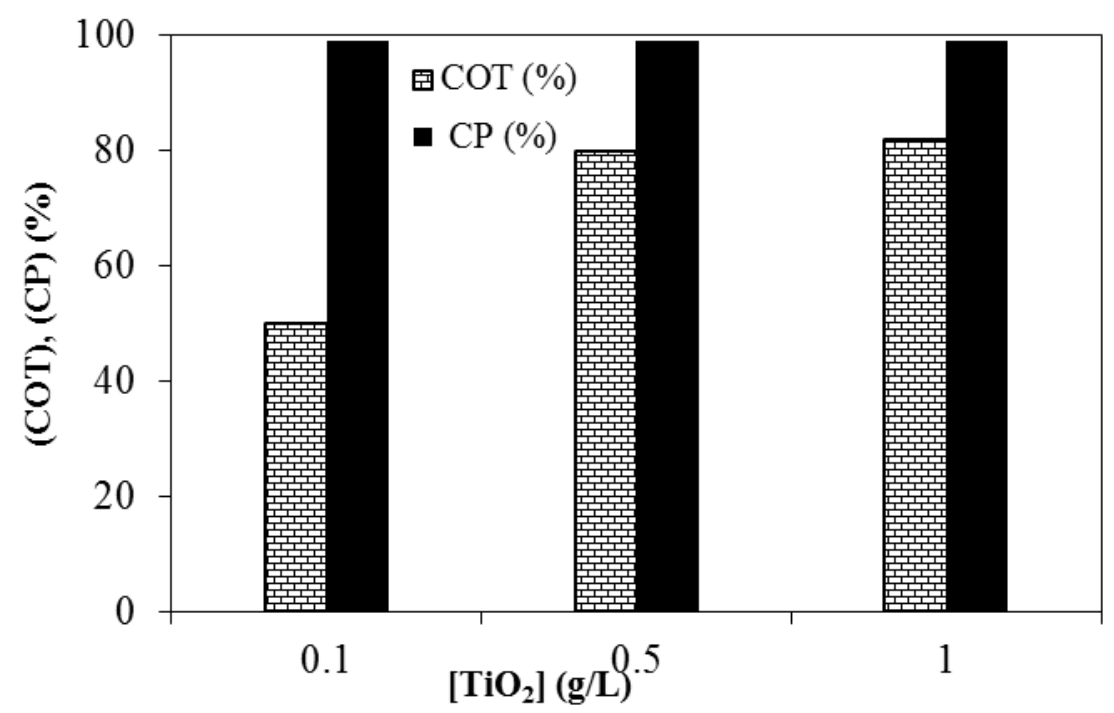

Figure 9:-Rate of mineralization and degradation of cyclophosphamide

\section{Conclusion:-}

In this study, $\mathrm{UVA} / \mathrm{TiO}_{2}$ process allowed the sizing of a system for depollution of water matrices contaminated by anti-cancer drugs. Photocatalytic degradation of ifosfamide and cyclophosphamide was studied in ultrapure water (model matrix) and in drinking water (drinking water). Efficacy of phototransformation of ifosfamide and cyclophosphamide reached its maximum of $0.5 \mathrm{~g} / \mathrm{L}$. On the other hand, this efficiency increases according to the dose of catalyst in drinking water. This highlights the effect of the chemical quality of the matrices on the degradation of the pharmaceutical molecules. The mineralization of these molecules could be satisfactory because of the concentrations of these molecules present in the doped matrices. Further studies will assess the effectiveness of coupling an absorption process on non-polluting materials and photochemical processes. 


\section{References:-}

1. Gupta, A.P., Pandotra, P., Sharma, R., Kushwaha, M., Gupta (2013). Chapter 8 - Marine Resource: A Promising Future for Anticancer Drugs. Studies in Natural Products Chemistry. 40, 229-325.

2. Andreani, T., Severino, P., Hollanda L.M., Vazzana M., Souto S.B., Santini A., Silva A.M., Souto E.B. (2017). Chapter 9 - Cancer therapies: applications, nanomedicines and nanotoxicology. Nanostructures for Cancer Therapy, 241-260.

3. Orias, F., and Perrodin, Y. (2013). Characterisation of the ecotoxicity of hospital effluents: a review. Science of the Total Environment, 454, 250-276.

4. Ferrando-Climent, F., Rodriguez-Mozaz, S., and Barceló, D., (2014). Incidence of anticancer drugs in an aquatic urban system: From hospital effluents through urban wastewater to natural environment. Environmental Pollution, 193, 216-223.

5. Franquet-Griell, H., Gómez-Canela, C., Ventura, F and Lacorte S. (2017). Anticancer drugs: Consumption trends in Spain, prediction of environmental concentrations and potential risks, Environmental Pollution, 229, 505-515.

6. Kosjek, T and Heath, E. (2011). Occurrence, fate and determination of cytostatic pharmaceuticals in the environment. TrAC Trends in Analytical Chemistry, 30 (7), 1065-1087.

7. Perrodin, Y., Christine, B., Sylvie, B., Alain, D., Jean-Luc, B.-K., Cécile, C.-O., Audrey, R., Elodie, B.A. (2013). Priori assessment of ecotoxicological risks linked to building a hospital, Chemosphere, 90 (3), 1037 1046.

8. Johnson, A. C., Jürgens, M. D., Williams, R., J., Kümmerer, K., Kortenkamp, A., and Sumpter, J. P. (2008). Do cytotoxic chemotherapy drugs discharged into rivers pose a risk to the environment and human health? An overview and UK case study. Journal of Hydrology, 348 (1), 167-175.

9. Mullot, J-U., Karolak, S., Fontova A. and Levi, Y. (2010). Modeling of hospital wastewater pollution by pharmaceuticals: first results of Mediflux study carried out in three French hospitals," Water Science \& Technology, 62 (12) 2912.

10. Seira, C. Sablayrolles, M. Montréjaud-Vignoles, C. and Joannis-Cassan C. (2016) Elimination of an anticancer drug (cyclophosphamide) by a membrane bioreactor: Comprehensive study of mechanisms. Biochemical Engineering Journal, 114, 155-163.

11. Kouadio, D.L., Traore, KS., Bekro Y.-A., Véronique M., Dembele A., Mamadou K., Mazellier P., Legube B., Houenou P. (2009). Contamination des Eaux de Surface par les Produits Pharmaceutiques en Zones Urbaines de Côte d'Ivoire : Cas du District D'Abidjan. European Journal of Scientific Research, 27 (1) 140-151.

12. Duong, H.A., Pham, N.H., Nguyen, H.T., Hoang, T.T., Pham, H.V., Pham, V.C., Berg, M., Giger, W., Alder, A.C., 200 (2008). Occurrence, fate and antibiotic resistance of fluoroquinolone antibacterials in hospital wastewaters in Hanoi, Vietnam, Chemosphere, 72 (6), 968-973.

13. Herrmann, J-M. (2005). Heterogeneous photocatalysis: state of the art and present applications in honor of Pr. R.L. Burwell Jr. (1912-2003), Former Head of Ipatieff Laboratories, Northwestern University, Evanston (Ill). Topics in Catalysis, 34 (1-4) 49-65.

14. Gaya, U.I., Abdullah, A.H., Zainal, Z., Hussein, M.Z., (2009). Photocatalytic treatment of 4-chlorophenol in aqueous $\mathrm{ZnO}$ suspensions: Intermediates, influence of dosage and inorganic anions, Journal of Hazardous Materials, 168 (1) 57-63.

15. Abellán, M.N., Bayarri, B., Giménez, J., Costa, J., (2007). Photocatalytic degradation of sulfamethoxazole in aqueous suspension of TiO2. Applied Catalysis B: Environmental, 74 (3) 233-241.

16. Wu, Q., Li, Z., Hong, H., Li, R., Jiang, W.-T., (2010). Phototransformation of selected organophosphorus pesticides: Roles of hydroxyl and carbonate radicals. Water Research, vol. 44, no. 12, pp. 3585-3594.

17. Chong, M.N., Jin, B., Chow, C.W., Saint, C., (2010) Recent developments in photocatalytic water treatment technology: a review," Water research, vol. 44, no. 10, pp. 2997-3027, 2010.

18. Kim, I. and Tanaka H. (2009). Photodegradation characteristics of PPCPs in water with UV treatment. Environment International 35 (5) 793-802.

19. Lutterbeck, C.A., Machado, Ê.L., Kümmerer, K., (2015). Photodegradation of the antineoplastic cyclophosphamide: A comparative study of the efficiencies of UV/H2O2, UV/Fe2+/H2O2 and UV/TiO2 processes. Chemosphere, 120, 538-546.

20. Fabiańska, A., Ofiarska, A., Fiszka-Borzyszkowska, A., Stepnowski, P. and Siedlecka E.M. 52015). Electrodegradation of ifosfamide and cyclophosphamide at BDD electrode: Decomposition pathway and its kinetics. Chemical Engineering Journal, 276, 274-282.

21. Lin, H.H.-H. and Lin, A.Y.C., (2014). Photocatalytic oxidation of 5-fluorouracil and cyclophosphamide via $\mathrm{UV} / \mathrm{TiO} 2$ in an aqueous environment. Water Research, 48, 559-568. 
22. Al-Hamdi A.M., Rinner, U. and Sillanpää, M., (2017). Tin dioxide as a photocatalyst for water treatment: A review, Process Safety and Environmental Protection, 107, 190-205.

23. N'guettia, K.R., Gombert B., Soro D.B., Traore, K.S. and Karpel, N.V.L., (2017). Dégradation photocatalytique du 5-fluorouracile par un système UV-A/TiO2 : effet de la concentration du catalyseur et du polluant, du pH et des matrices de dilution. International Journal of Biological and Chemical Sciences, 11, (3), 1373-1385.

24. Choi, J., Lee, H., Choi, Y., Kim, S., Seokheon, L, Seunghak, L., Choi, W., Lee, J. (2014). Heterogeneous photocatalytic treatment of pharmaceutical micropolluants: Effects of wastewater effluent matrix and catalyst modifications. Applied Catalysis B : Environmental, 147, 8-16.

25. Doré, M., Chimie des oxydants et traitement des eaux. Lavoisier, 1989.

26. Ziegmann, M., Doll, T. and Frimmel, F.H., (2006). Matrix effects on the photocatalytical degradation of dichloroacetic acid and atrazine in water, Acta hydrochimica et hydrobiologica, 34 (1-2) 146-154.

27. Gad-Allah, T.A., Ali, M.E., and Badawy, M.I., (2011). Photocatalytic oxidation of ciprofloxacin under simulated sunlight. Journal of hazardous materials, 186 (1) 751-755.

28. Hapeshi, E., Achilleos, A., Vasquez, M.I., Michael, C., Xekoukoulotakis, N.P., Mantzavinos, D., Kassinos, D., (2010). Drugs degrading photocatalytically: Kinetics and mechanisms of ofloxacin and atenolol removal on titania suspensions. Water Research, 44 (6) 1737-1746. 